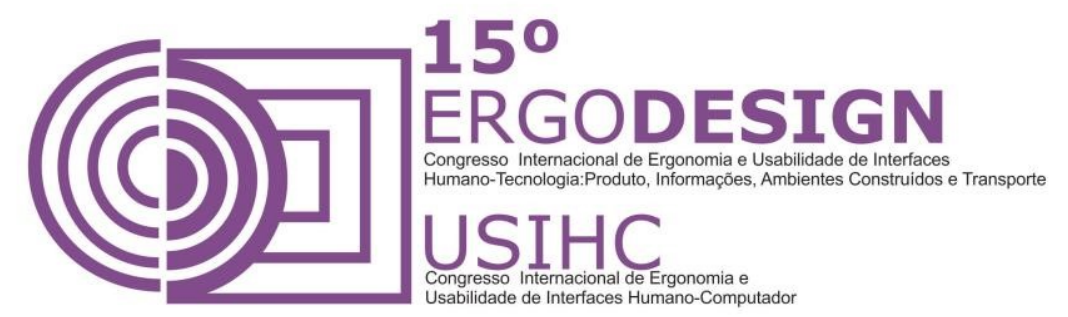

\title{
RELATO DE EXPERIÊNCIA: A ERGONOMIA DE CONCEPÇÃO NO DESENVOLVIMENTO DE PRODUTOS DO VESTUÁRIO DE MODA INCLUSIVA
}

\author{
EXPERIENCE REPORT: THE DESIGN OF ERGONOMICS IN \\ DEVELOPMENT OF FASHION PRODUCT INCLUSIVE \\ SIMÕES-BORGIANI, Danielle Silva (1); \\ SILVA, Demócrito José (2); \\ SANTOS, Juliana de Souza (3); \\ LIMA, Mônica da Cunha (4); \\ SILVA, Jacqueline Gilcelli A. (5); \\ NEIVA, Elaine César (6); \\ (1) Faculdade Senac Pernambuco, Doutora, \\ E-mail: danielle@simoes-borgiani.com
}

(2) (3) (4) (5) (6) Faculdade Senac Pernambuco, graduando

E-mail: jacgil.silva@gmail.com

\begin{abstract}
RESUMO
O presente trabalho apresenta o relato de experiência da ergonomia como ferramenta para desenvolvimento produtos de moda inclusiva. A experiência foi vivenciada na Faculdade Senac Pernambuco, no curso de Tecnologia em Design de Moda, onde Ergonomia é Componente Curricular e faz parte do projeto integrador interdisciplinar do primeiro módulo do curso. Palavras-chave: Design de Moda, Ergonomia do Vestuário, Moda Inclusiva.

Palavras-chave: Design de Moda, Ergonomia do Vestuário, Moda Inclusiva.

\section{ABSTRACT}

This paper presents the ergonomics of experience report as a tool for developing inclusive fashion products. The experience was lived in the Faculty Senac Pernambuco, in the course of Technology in Fashion Design, where ergonomics is Course Component and is part of the interdisciplinary project integrator of the first module of the course. Keywords: Fashion Design, Clothing Ergonomics, Inclusive Fashion.
\end{abstract}

Keywords: Fashion Design, Clothing Ergonomics, Inclusive Fashion. 


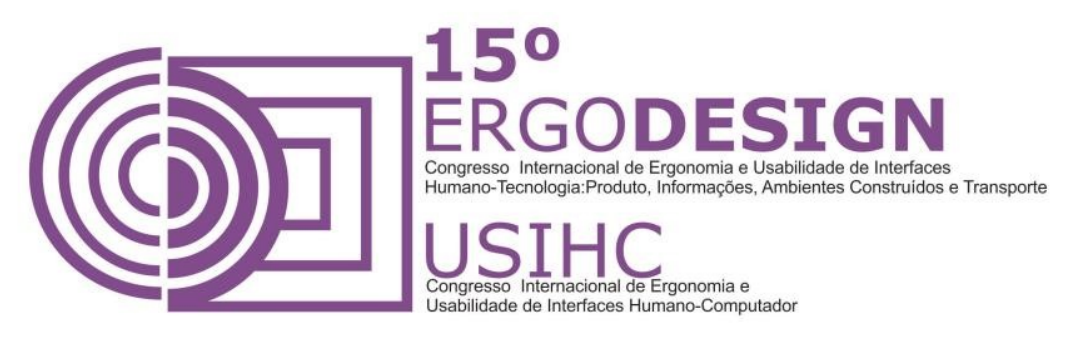

\section{INTRODUÇÃO}

Na perspectiva de um novo olhar, onde a necessidade de incluir e igualar ultrapassou a barreira do modismo, se tornando uma necessidade real e até mesmo uma oportunidade de negócio, a moda inclusiva torna-se imperativa nas sociedades atuais.

Segundo Garcia (2011), 45 milhões de brasileiros possuem algum tipo de deficiência. Embora o número seja expressivo, nem sempre esse público é atendido no mercado de consumo.

Diante disto, no primeiro módulo do curso superior de Tecnologia em Design de Moda, é apresentado ao aluno o projeto integrador que culmina com a finalização do primeiro módulo e integra as seguintes unidades temáticas: Ergonomia aplicada ao vestuário, Modelagem Tridimensional, História e Estética da Indumentária, Tecnologia Têxtil e Desenho de Moda. Cada unidade temática contribui para o desenvolvimento de uma coleção de moda inclusiva. $O$ aluno é levado a refletir, inferir e decidir sobre a vestimenta ergonomicamente adequada para uma necessidade especial.

\section{RELATO DE EXPERIÊNCIA}

A moda inclusiva tem como finalidade aproximar e incluir pessoas de forma a humanizar a moda (GONÇALVES, 2013). Embora muitos esforços tenham acontecido, ainda percebe-se carência dos dois lados: do mercado e do portador de necessidades especiais. Muitas vezes não há produtos no mercado preparados para as necessidades especiais, outras vezes o portador de necessidade também não sabe qual melhor tecido, modelo e uso de peças do vestuário que the servem.

Diante desta realidade, a equipe de trabalho optou por pesquisar pessoas com alguma debilidade motora e assim foi definido o estudo na hemiplegia. Em seguida, elencou-se nos períodos históricos estudados aquele que poderia servir como referência estética para coleção de vestidos de festa de moda inclusiva. O Egito foi definido pelo grupo e alguns elementos que remetem ao Egito foram escolhidos para darem referências estéticas as roupas.

A ergonomia utilizada foi de concepção. Todas as diretrizes criativas utilizadas pelo grupo, tinham princípios embasados no bem-estar, vestibilidade, mobilidade e facilidade de manuseio. O produto desenvolvido, a coleção, foi concebido com qualidades estéticas, técnicas e ergonômicas. Segundo lida(2003), entende-se por qualidade técnica a eficácia na execução das funções e facilidade de manutenção (manuseio e limpeza); por qualidade estética entende-se a combinação de cor, forma e textura para conferir um visual agradável e ergonômicas são as qualidades que se referem a compatibilidade de movimentos, conforto, segurança e adaptação antropométrica. Estas qualidades foram utilizadas para gerar as soluções na coleção (tabela 1).

Tabela 1. Relação entre as qualidades do produto e soluções na coleção. 


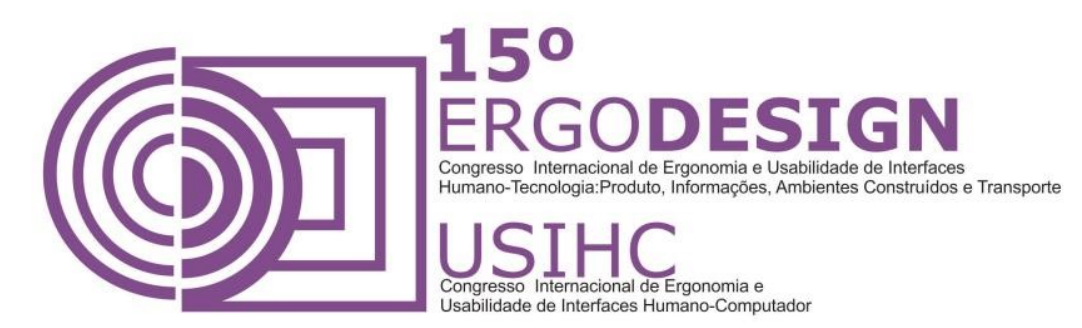

Técnicas - a eficácia na execução das funções e facilidade de manutenção (manuseio e limpeza)

Ergonômicas - a compatibilidade de Comprimento da roupa no tornozelo para evitar quedas movimentos, conforto, segurança e adaptação antropométrica.

Tecido de fácil lavagem e manutenção (não precisa passar)

Fechamento da roupa frontal por zíper para dar autonomia ao usuário de fechar com poucos movimentos e apenas uma mão.

Ombros largos (evitar uso de alças) ou mangas nas roupas para melhor sustentação, considerando que um dos braços é levemente pronunciado para baixo pela falta de movimento.

Estéticas - combinação de cor, forma e textura para conferir um visual agradável

Uso de drapeados em referência ao Egito e as tendências atuais

Cor azul, verde e preto como referência Egípcia

Uso de pala com pedrarias

Textura de drapeado

A coleção recebeu o nome de Flor de Lótus, desenvolvida como proposta de uma segunda pele confortável, atual e inclusiva proporcionando as pessoas hemiplégicas a inclusão. A moda inclusiva tratada neste artigo e na coleção proporciona tanto para pessoas comuns como as que portam deficiência a possibilidade de vestir a mesma roupa, o mesmo modelo, sem alterações.

O recurso de trazer o zíper para parte frontal e diminuir o comprimento dos vestidos tornou a roupa acessível aos hemiplégicos que teriam dificuldade de sozinhos fechar o zíper se estivesse nas costas. A limitação dos movimentos sugere pequenas adaptações na roupa mas não tolhe a possibilidade de usar modelos contemporâneos (Figura 1A).
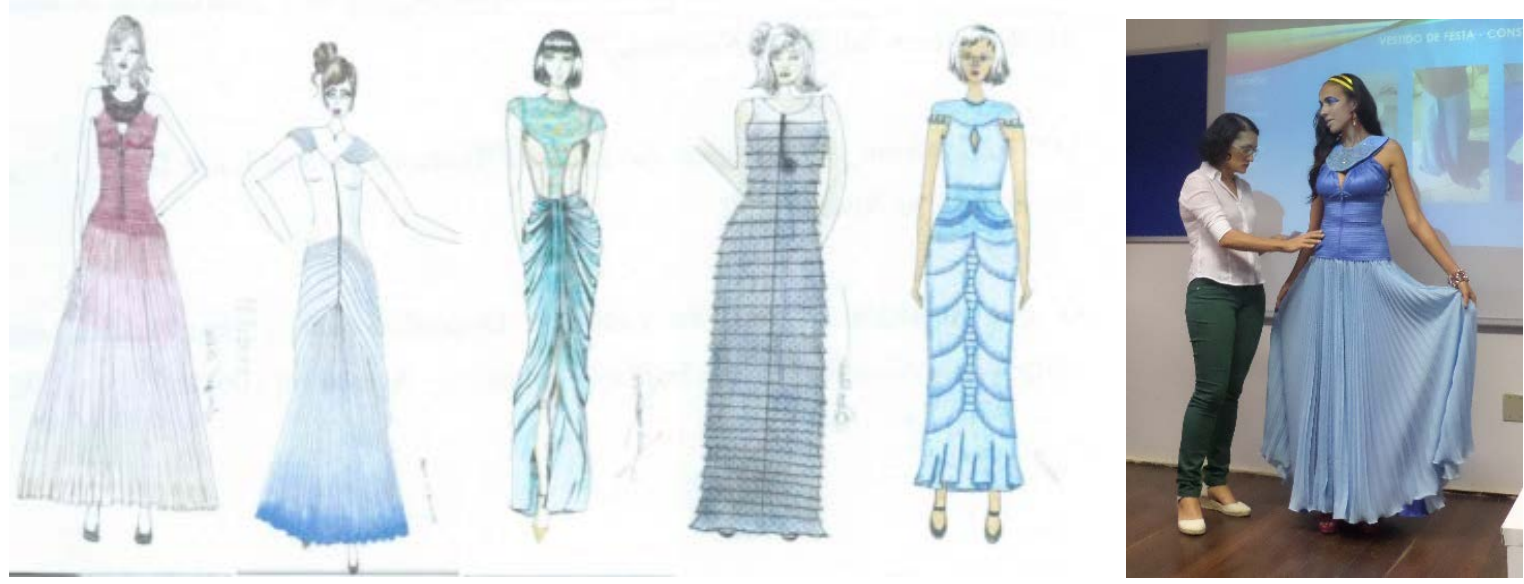

Figura 1. (A) Croquis do segmento Festa da coleção Flor de Lotus. (B) Apresentação da coleção Flor de Lotus. Fonte: Própria. 


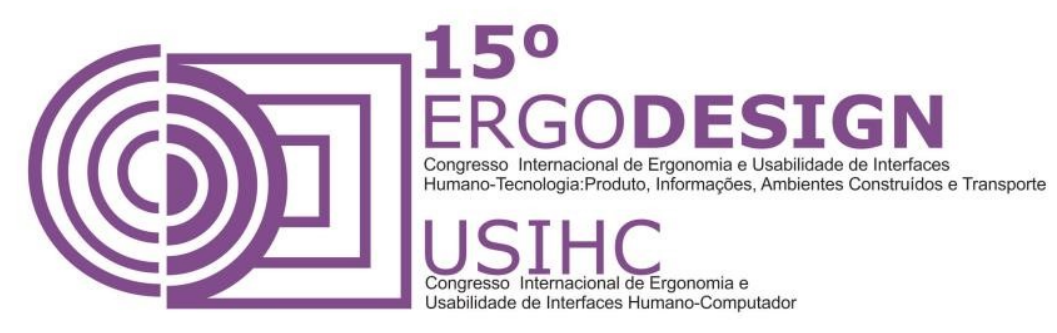

Para apresentação do projeto final, uma peça da coleção foi confeccionada e apresentada para uma comissão docente que avaliou: escolha de tecido e relação com a necessidade especial, referências históricas empregadas de forma contemporânea, modelagem da peça de acordo com as necessidades do corpo do hemiplégico, representação gráfica da peça (croqui) e finalmente a inclusão proposta pela vestimenta (Figura 1B). O projeto proporciona aos discentes um olhar sobre a moda inclusiva sob a ótica da ergonomia e características do produto, fundamentais na formação em design de moda.

\section{REFERÊNCIAS BIBLIOGRÁFICAS}

GARCIA, V. 45 milhões de brasileiros com deficiência: censo 2010 reforça desafio do Brasil em dar uma vida digna aos deficientes. In: Deficiente ciente, 2011. Disponível em: Acesso em: 10 de fevereiro de 2015.

GONÇALVES, L. P. Roupas para pessoas com deficiência, estudo de caso sobre a influência das roupas no comportamental dessas pessoas, uma reflexão sobre inclusão e moda. In: Colóquio de Moda, 9, Anais: Fortaleza, 2013.

IIDA, Itiro. Ergonomia Projeto e Produto. São Paulo: Edgard Blucher, 2003. 